\title{
Features of Human Immunodeficiency Virus Infection and Disease
}

\author{
JAY A. LEVY \\ Department of Medicine and Cancer Research Institute, University of California School of Medicine, \\ San Francisco, California 94143-0128
}

\begin{abstract}
Characteristics of human immunodeficiency virus (HIV) strains and the host immune response against the virus are major determinants in the pathogenesis of AIDS. HIV isolates can be distinguished by their ability to infect and replicate to high titers in cells, to kill those cells, and to down-modulate the CD4 protein on the cell surface. In addition, their sensitivity to serum neutralization or enhancement of infection can be appreciated. The genetic sequences associated with these biologic and serologic properties have been localized and could eventually be helpful for antiviral therapy. These variations in properties of HIV strains appear to correlate with induction of neurologic and gastrointestinal disease by certain strains. In some cases, HIV can establish a silent, latent infection. The mechanisms involved are not well defined, but one concept involves the nef gene, which with some strains, can suppress virus replication. An important finding is that viruses recovered from individuals as they advance to disease have many properties in vitro of presumed virulence in the host, such as a wide cellular host range, cytopathicity, and resistance to the antiviral effect of Nef. The host immune response can control virus spread through antiviral antibodies or cellular immune responses. Neutralizing antibodies are not commonly found in infected individuals, suggesting that viruses "escape" this immune response. Instead, in some symptomatic patients, antibodies that enhance virus infection can be detected. The difference in sensitivity of a virus appears related to its envelope proteins. Cellular immune responses offer some promise in maintaining or eliminating virus infection. CD8+ cells with both cytotoxic and suppressing activities have been described, and their antiviral effect is strongest in asymptomatic infected individuals. The clinical relevance of these biologic studies is evident in long-term survivors who appear infected by viruses with less virulent properties, have no enhancing antibodies, and have a strong CD8+ cell response. (Pediatr Res 33 (Suppl): S63-S70, 1993)
\end{abstract}

\section{Abbreviations}

ADE, antibody-dependent enhancement

CPE, cytopathic effect

HIV, human immunodeficiency virus

sCD4, soluble CD4

GI, gastrointestinal system

AIDS involves the usual three major components of infection: a causative agent (HIV), the host cells sensitive to infection, and

Correspondence: Jay A. Levy, M.D., Department of Medicine and Cancer Research Institute, University of California School of Medicine, San Francisco, CA 94143-0128. the immune response to the agent by the infected individual. In the case of retroviruses, the infection occurs with the reverse transcription of an RNA genome into a DNA form that integrates into the host cell chromosome. Within this cellular genetic material, the virus persists as an intracellular parasite that can either destroy the cell it infects through CPE or remain within it as a latent or persistent infection. The extent of virus spread, its degree of cell killing, and its ability to compromise (or escape from) the immune response of the host define the parameters that determine the pathogenic potential of HIV. Certain of these biologic and immunologic features of HIV infection are discussed in this article.

\section{BIOLOGIC PROPERTIES OF HIV}

Cellular host range. HIV, the etiologic agent of AIDS, was originally thought to infect only CD4+ lymphocytes via the CD4 receptor molecule $(1,2)$. Subsequent work indicated that many other hematopoietic cells, particularly macrophages, can be infected by this virus $(3,4)$. Moreover, other evidence has shown that CD4- cells are also susceptible to HIV infection $(5,6)$. The potential cellular host range of this lentivirus now includes nearly every cell type within its human host (Table 1). Several tissues in the body can be infected, some of which reflect evidence of a direct pathogenic effect of this agent. Thus, HIV is a polytropic and not solely a T-lymphotropic virus.

Virus/cell interaction, virus entry. Because HIV initially infected CD4+ lymphocytes, the discovery of the CD4 molecule as a major receptor for the virus was not too surprising. Its detection helped to define a variety of cell types, some of them in the brain, that express this molecule and thus would appear to be susceptible to the virus. However, some CD4+ T cells cannot be infected by HIV (7), and, as noted above, some CD4cells have been found to be susceptible to the virus (Table 1). Therefore, the initial conclusion that virus attachment to CD4 via the envelope gp120 was sufficient for viral entry has been challenged. The similarity of a fusion molecule on the HIV envelope gp41 to that of paramyxoviruses (8) has suggested that attachment and fusion are two steps in this entry process (9).

More recently, a protease inhibitor-like region, located within the viral gp120 [particularly in the V3 (variable) loop], was identified. A concept was then proposed that viral entry might depend on cleavage of this HIV protein by a cellular protease $(10,11)$. Under this hypothesis, an interaction of the viral envelope with a cell surface receptor (in most cases the CD4 molecule) occurs initially. After HIV attachment, the viral envelope is cleaved by a cellular protease, which could be cell-type specific. Virus entry subsequently takes place via a gp 41 -mediated fusion with a different receptor on the cell surface. Obviously, if CD4 is not present, an alternative binding receptor could be used or cleavage and fusion alone might take place (9). In the case of certain CD4- brain-derived cells, a galactosylceramide (GalC) has recently been found to participate as a receptor for HIV infection of these cells (12). Being a glycolipid, GalC, as in the 
Table 1. Human cells* susceptible to HIV

\begin{tabular}{l} 
CD4+ \\
T lymphocytes \\
B lymphocytes \\
Primary monocytes/macrophages \\
Monocyte cell lines \\
Bone marrow precursor cells \\
Dendritic cells \\
Langerhans cells \\
Brain microglia \\
Colon carcinoma cells \\
CD4- \\
Glioma cell lines \\
Neuroblastoma cell lines \\
Osteosarcoma cell line (HOS) \\
Hepatoma cell line \\
Rhabdomyosarcoma cell line (RD) \\
Fetal astrocytes \\
Skin fibroblast cells \\
Fetal adrenal cells \\
Bowel epithelial cells \\
Transformed trophoblast cells \\
\hline
\end{tabular}

* Studied in tissue culture.

case of paramyxovirus, could be the fusion receptor for HIV on some cells.

Thus, the proposed use of sCD4 to block the extent of virus infection and its spread in the host (13) warrants further evaluation. In this regard, fresh virus isolates from infected individuals appear to be less sensitive to SCD4 than standard laboratory strains (14). The reason could be a greater affinity of the fresh virus isolates for the CD4 present on CD4+ lymphocytes than for SCD4. Clearly, all these factors need to be considered in therapies directed at early events in HIV infection.

Cytopathology. During the initial recovery of HIV, alterations in the infected peripheral lymphocytes were noted (15-17). In particular, the formation of multinucleated cells and ballooning of the cell membrane with subsequent cell degeneration were described (18). The cause for these CPE is not yet defined, but several hypotheses have been proposed, including disturbance to the cell membrane with an influx of monovalent and divalent cations, accumulation of unintegrated DNA, and toxic effects of viral proteins $(9,19)$. In our laboratory and others, it has been noted that the extent of cytopathology can be measured by a plaque assay using an MT-4 T-cell line attached to plastic plates by poly-L-lysine. By this procedure, the most cytopathic viruses for CD4+ lymphocytes are those that induce plaques in this cell line that can be identified by syncytial formation and cell death (20) (Fig. 1).

Heterogeneity of virologic features. The biologic features discussed briefly above can be shown to differ among various HIV1 and HIV-2 strains. The viruses vary not only in their ability to infect certain cells, but also in the speed in which they replicate (i.e. kinetics), as measured by the early peak of virus replication and the level of virus replication (21). Some groups refer to these differences as "rapid/high" and "slow/low" virus subtypes (22). These distinctions, however, are not always clear, inasmuch as some slow/high and rapid/low viruses have been isolated. Finally, the extent to which HIV can induce cytopathology can vary substantially among strains. As noted above, this parameter can be observed readily by the MT-4 plaque assay. This cell culture procedure can reflect differences in HIV cytopathicity by not only the formation but also the size of the plaques.

\section{VIRUS INFECTION AND DISEASE}

Immune disorders. As noted above, $\mathrm{HIV}$, after infecting CD4+ lymphocytes, can lead to CPE, with rapid destruction of these cells. With some virus strains, however, the CD4+ lymphocytes can persist for several months, releasing virus without undergoing

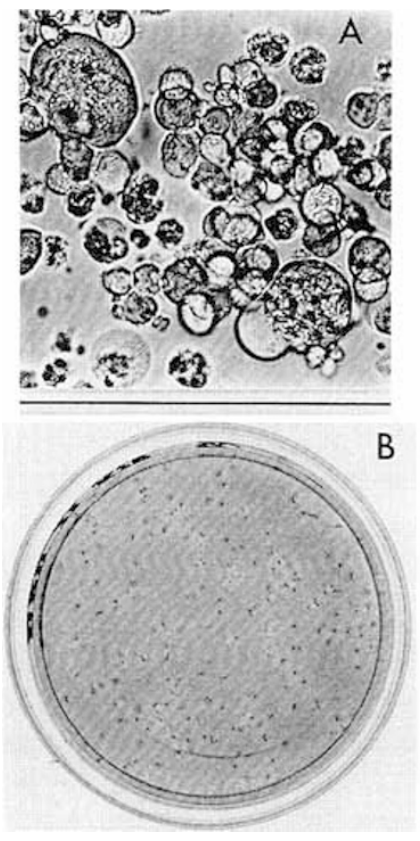

Fig. 1. Plaque formation in the MT-4 cell line. $A$, Peripheral blood mononuclear cells showing CPE of the HIV-1 $1_{\mathrm{SF} 33}$ strain. $B$, Plaques formed in the MT-4 cell line by the HIV-1 $1_{\mathrm{SF} 33}$ strain.

cell death (23). Nevertheless, the function of these cells is most likely compromised. Many immunologic disorders have been described in HIV infection and are considered the reason for the opportunistic infections and malignancies that develop with AIDS. Yet the way in which the virus specifically affects the $T$ cell, macrophage, or stem cell to effect these modifications is not clear. The eventual loss of CD4+ lymphocytes is still a mystery because it cannot be explained solely by direct infection (19). Other factors involved could include cytotoxic CD8+ cells, cytokine production, and autoimmune responses (19). The relative contribution of these phenomena to the final loss of a sufficient immune response to ward off disease requires more study.

Neurologic disease. Many HIV-infected individuals will, with time, develop signs of CNS disorders (24). Some of these individuals present with signs of dementia and other neurologic diseases without a marked decrease in their CD4:CD8 ratios. We initially saw such a patient in early 1984 . He was a homosexual man who presented with complaints of not working as well as he had formerly as a computer expert. Over a period of $6 \mathrm{mo}$, this individual developed seizures, went into a coma, and died. $\mathrm{He}$ had a nearly normal helper:suppressor ratio, and the cause of his neurologic symptoms was unknown. Interestingly, 2 y previously, his lover had died of the same kind of CNS disorder. At autopsy, we isolated HIV from his brain as well as lymph nodes (25) and have now characterized several other HIV strains obtained from the CNS. These studies have indicated that viruses causing disease in the brain can be distinguished by a variety of biologic and serologic properties (26) (Table 2). Recently, differences in genetic sequences between viruses in the CNS and blood in the same individuals have been reported (27). These results all indicate that an individual can carry several related viruses in the body, and these agents can differ by biologic as well as molecular features. Thus, an initial infecting virus appears to evolve within the host to have a particular cell tropism and potential pathogenesis in the tissue infected.

The isolation and the characteristics of the viruses in the brain mirror the finding of HIV in a variety of cells in the CNS, particularly macrophages, but also glial cells and perhaps neurons (28). How disease is caused in the brain, however, is not known. It probably involves a variety of processes, including cytotoxic products of infected macrophages, direct effects of viral proteins on cells, and disturbances of the cell membrane, via the viral 
Table 2. Potential characteristics of neurotropic HIV strain

\begin{tabular}{lcc}
\hline & \multicolumn{2}{c}{ HIV-1 isolate* } \\
\cline { 2 - 3 } \multicolumn{1}{c}{ Viral characteristics } & Blood & Brain \\
\hline Growth in CD4+ lymphocytes & +++ & +++ \\
Cytopathic for CD4+ lymphocytes & ++ & - \\
CD4 down-modulation & ++ & - \\
Growth in T-cell lines & +++ & - \\
Growth in macrophages & + & +++ \\
Plaques in MT-4 cells & ++ & - \\
Sensitivity to serum neutralization & +++ & + \\
\hline
\end{tabular}

* The relative extent of viral activity is indicated by the number of plus signs.

Table 3. Characteristics of HIV strains associated with virulence in host

Enhanced cellular host range

Rapid kinetics of replication

High titers of virus production

Efficient cell killing

Lack of sensitivity to suppression by the Nef protein

Sensitivity to antibody-dependent enhancement of infection

envelope, leading to poor nerve transmission $(19,29)$. The most recent hypotheses focus on the effect of envelope gp 120 and the tat protein $(30,31)$, and the toxic consequences of small molecular weight substances produced by infected macrophages (32, 33).

GI system. Several patients, particularly in the chronic state of HIV infection, can present with persistent, watery diarrhea. In Africa, this condition has been called "Slim's disease" because of the malabsorption and extensive weight loss that occurs (34). In some of these individuals, no other sign of a causative pathogen except for HIV has been found. The virus has been located by in situ hybridization in the crypts of the bowel-in columnar and goblet cells, as well as enterochromaffin cells (35). The latter cells are important for normal motility and digestion in the bowel (36). Recent evidence indicates that HIV can be distributed in cells throughout the GI system (37). Moreover, its presence in the mucosal lining of the rectum suggests that this organ is one of the first routes of transmission during anal-genital activity. This conclusion is supported by epidemiologic data indicating that lavage of the anal canal is an additional parameter that increases HIV transmission (38). Viruses coming from the GI tract can also be distinguished, by biologic and molecular features, from those recovered from the blood (39), but not with the same degree of difference as with brain isolates. Nevertheless, the variations noted suggest that the kind of viral evolution occurring within the brain may also be occurring in the GI system. How HIV causes GI disorders is not known, but the hypotheses include those cited for the CNS: direct infection of bowel cells and indirect effect of toxic cellular or viral factors (19).

Changes in HIV in same individual over time. One of the important questions in pathogenesis is why one individual, after infection, will progress to disease rapidly, whereas another takes a long time to develop symptoms. One parameter could be the properties of the virus itself. Cecilia Cheng-Mayer et al. (40) in our laboratory first demonstrated that following an individual over time can reveal differences in the viruses recovered when the individual is healthy versus when the individual has developed disease. The later isolate shows certain characteristics in tissue culture that would correlate with "virulence" in vivo (Table 3 ). These include a wide cellular host range, replication rapidly to high titer in the infected cells, and a high cytopathicity (19). Molecular studies indicate that the early and late isolates are related, but obviously changes occur over time to make the virus appear to become more pathogenic. How this more "virulent" virus develops in the host is not known. It could be present initially and get suppressed by an active immune system. Alternatively, it could emerge during the course of infection, after multiple replications with mutations.

\section{SEARCH FOR VIRULENCE GENE(S)}

With the heterogeneity among viral strains recognized, certain regions of HIV that correspond with the cytopathic and biologic features described can potentially be identified. Using interviral recombinants of HIV-1 strains that have known, distinguishing biologic properties, we and others have been able to narrow down substantially the region of HIV that gives rise to host range differences, cytopathology, and sensitivity to serum neutralization $(41-45)$.

In most cases, the region for cell tropism appears to be in the viral gp 120 and, in recent studies, limited for some viruses to the V3 region (44, unpublished observations) - the portion playing a major role in viral neutralization (46). A summary of observations made with two related but distinct virus isolates (HIV$1_{\mathrm{SF} 2}$ and HIV-1 $1_{\mathrm{SF} 13}$ ) is shown in Figure 2. With these HIV-1 strains, nonoverlapping regions in the gp 120 appear to influence infection of certain cell types (45). Notably, infection of the HUT 78 and MT-4 T-cell line, as well as peripheral blood macrophages, involves one portion of gp 120 (including the V3 region), whereas U937 and CEM infection involve another (Fig. 2) (45). The latter observation supports the conclusion that the U937 monocytic cell line is not an ideal one to use for host range studies of peripheral blood macrophages.

In most recent studies, Tatsuo Shioda and our group have demonstrated that as few as three amino acid changes in the V3 loop can convert a T-cell-tropic virus into a macrophage-tropic virus (unpublished observations). Moreover, only one amino acid change in the V3 loop can eliminate the ability of a virus to infect a T-cell line (e.g. MT-4). These observations are dramatic and emphasize how very small changes in the HIV envelope might influence relative infection rates and spread in a host. Nevertheless, most data suggest that many amino acid changes are required to cause major alterations in the tropism of the virus, and some of these are not linked but appear in regions outside the V3 loop (unpublished observations, 47).

The domain correlating with enhanced cytopathology has been found in some studies within the same envelope portion as the

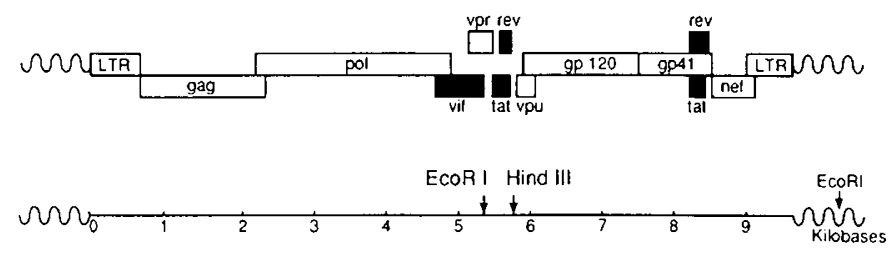

(a)

$$
\longmapsto \text { Replication KInetics }
$$

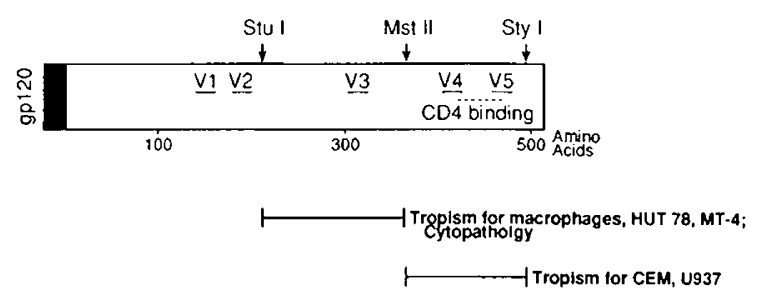

Fig. 2. Schematic representation of the viral genome regions determining biologic properties associated with $\mathrm{HIV}-1_{\mathrm{SF}_{2}}$ and its related strain, $\mathrm{HIV}-1_{\mathrm{SF} 13} . a$, Region of the virus associated with increased replication kinetics as demonstrated with HIV-1 $1_{\mathrm{SF} 13} . b$, Portion of the envelope gp120 associated with cell tropism and cytopathology. Amino acid numbering is according to the coding sequence of HIV-1 $1_{\mathrm{SF} 2}$. (Reprinted from ref. 80 with permission from the publisher.) 
HUT 78 cell tropism (45). This latter biologic feature needs to be more precisely defined by further molecular procedures. Some reports indicate, however, that only one or two glycosylation site changes in the gp120 can influence the extent of cell killing by HIV (48). Finally, the specific regions in the viral envelope (particularly gp 120) sensitive to neutralization are now being defined by molecular studies.

\section{LATENCY}

Besides giving rise to productive and cytopathic infection, HIV can induce a state in which very little viral protein, RNA, or infectious progeny virus is produced. This latent state can permit long-term persistence of the virus within the host and is accompanied by very few symptoms, if any. The phenomenon would clearly permit long-term survival of both HIV and its host. The cause of latency is not known, and a variety of hypotheses have been considered, including viral DNA methylation, inactivation of the tat gene, and the persistence of the Nef protein $(49,50)$.

The latter concept was proposed after observing that when the nef gene is deleted from a viral DNA clone, the resulting infectious HIV replicates to much higher titer and is more cytopathic than the parental strain (49). These findings suggested that the Nef protein suppresses virus replication and thus could be responsible for a "silent" state. This hypothesis has received support from the observations by Cheng-Mayer et al. (51) that when the Nef protein is introduced by molecular techniques into $\mathrm{T}$-cell lines, HIV-1 replication can be suppressed, although virus entry and integration take place. A notable finding has been that the more cytopathic viruses are resistant to the effects of Nef (51). Thus, viruses isolated early from a healthy individual show a sensitivity to Nef, whereas viruses recovered later, when the same individual has AIDS, are resistant to the suppressive effects of the Nef protein (Table 3).

Most recent studies with molecular clones of the sensitive and resistant viruses have strongly suggested that the effect of Nef results in an anti-Rev-like activity (52). In T-cell lines expressing Nef, only small species of mRNA of the sensitive HIV-1 $1_{\mathrm{SF} 2}$ strain are made. The large mRNA species that would code for the viral proteins necessary for an infectious particle are blocked. Moreover, interviral recombinants of the SF2 strain and its related SF13 strain indicate that the viral sequence associated with the response to Nef involves part of gp41, tat, and Rev. Thus, we conclude that Nef either binds to Rev or its responsive element in the envelope or interacts with cellular proteins to prevent the effect of the Rev regulatory protein.

\section{HOST IMMUNE RESPONSES TO HIV}

Neutralization/enhancement. Evidence accumulated over the past $6 \mathrm{y}$ now indicates that antibodies can be present in most infected individuals that will neutralize HIV strains, particularly those grown in the laboratory $(53,54)$. A noteworthy finding is that, early in the course of disease, subjects may neutralize the autologous strain (the one present in their bodies) but later show no neutralizing activity against the same strain. Instead, as demonstrated by Homsy et al. (55), the antibody present in the blood of symptomatic patients may enhance the infectivity of the autologous HIV strain. Thus, this characteristic is another feature of HIV that is associated with virulence in the host (Table 3 ). This ADE of HIV infection appears to be mediated both by the complement and $\mathrm{Fc}$ receptors $(56,57)$ and has been noted in many individuals who are infected by the virus. Moreover, certain animal species (e.g. guinea pigs) immunized with virus or the viral envelope can show enhancing antibodies to certain strains, whereas they may have neutralizing antibody to the strain used for immunization (58). Finally, some sera from infected individuals can show neutralizing activity against one strain (e.g. $\left.\mathrm{HIV}-1_{\mathrm{SF} 2}\right)$ but enhancement of another $\left(e . g . \mathrm{HIV}-1_{\mathrm{SF} 170}\right)(58)$.

It is noteworthy, as demonstrated recently by Kliks et al. (59), that the same MAb can show neutralizing or enhancing activity, depending on the HIV-1 strain used. Very small changes within the V3 loop can determine whether a virus is neutralized or enhanced by a particular antibody species (59). This observation suggests ways in which the virus could escape an immune response of the host. A small amino acid change might determine the relative sensitivity to neutralization by an antibody and thus the pathogenicity of the viral strain.

The enhancing antibodies not only increase infection of macrophages, but also CD4+ lymphocytes and even fibroblasts (56). In some cases, the CD4 molecule is involved $(60,61)$; in others, it is not (56). This points out the need for another caution about the universal use of $\mathrm{sCD} 4$. The envelope region responsible for ADE appears to be located within gp120 for the Fc-mediated response (59) and within gp41 for the complement-mediated activity (62). Additional work should define distinct epitopes. Finally, a potential cofactor role of herpes viruses is suggested by studies of $\mathrm{ADE}$. Herpes viruses induce $\mathrm{Fc}$ receptors on infected cells (63) and, as shown with cytomegalovirus, could convert cells into sensitivity to infection via antibody/HIV complexes (64).

The clinical relevance of neutralization for protection after infection is not known, inasmuch as neutralizing antibodies are present in symptomatic patients (65). Enhancing antibodies that have been linked to increased disease prevalence with certain other viruses (66) merit particular attention. As noted above, AIDS patients can have antibodies of this type in their blood, and long-term survivors lack this immunologic response.

Cellular immune response. In most viral infections the cellular immune response is vital for the complete arrest of the infectious agent. For HIV, the cells involved include a variety of immune cells, including natural killer cells and CD8 $+\mathrm{T}$ cells. The latter cell type has shown both cytotoxic and suppressing activity against HIV infection (67-69). The cytotoxic response has been demonstrated against a variety of viral antigens associated with regulatory as well as structural proteins (68). This response decreases with advancement of disease in individuals. Thus, it could have important clinical relevance.

Our laboratory has concentrated on the antiviral-suppressing activity of CD8 + lymphocytes (69). This observation was made when it was found that cultured peripheral blood mononuclear cells from asymptomatic individuals did not generally release virus in culture. When the CD8+ cells were removed, virus could easily be recovered (67). Subsequently, CD8+ cells returned to the peripheral blood mononuclear cell culture suppressed the growth of the virus. This suppressing activity is readily demonstrated by mixing CD8+ lymphocytes with infected CD4+ lymphocytes $(67,69,70)$. Virus replication is blocked without killing the infected cell. The extent of CD8+ cell-suppressing activity varies according to the clinical state. Asymptomatic individuals have a high level of this antiviral response; as few as one CD8+ to $20 \mathrm{CD} 4+$ cells can be effective. In contrast, CD8+ cells from patients with AIDS sometimes show very little, if any, ability to suppress virus replication in CD4+ cells (70).

The mechanism for this CD8 + cell activity involves, in part, a cellular factor that suppresses HIV-1 replication in culture without killiiig tne cell (71). Most recent studies indicate that the cellular factor is a novel cytokine that has no relationship to any of the known antiviral factors, including the interferons and tumor necrosis factor (52). The mechanism of action also appears to be distinct from that of these agents. The CD8+ cell factor suppresses virus RNA transcription after viral integration (72). We believe this cellular immune response is very important in controlling HIV infection. In this regard, long-term survivors have very strong $\mathrm{CD} 8+$ cell-suppressing activity.

Autoimmunity. One other aspect of the immune response in HIV infection is the production of autoantibodies that may be directed to various cellular proteins (9). These can give rise to autoimmune diseases inducing neutropenia, thrombocytopenia, and peripheral neuropathy (Table 4 ). Several regions of HIV can 
Table 4. Autoantibodies detected in HIV infection

\begin{tabular}{ll}
\hline \multicolumn{1}{c}{ Antibodies to } & \multicolumn{1}{c}{ Associated clinical condition } \\
\hline Lymphocytes & Loss of CD4+, CD8+, B lymphocytes \\
Platelets & Thrombocytopenia \\
Neutrophils & Neutropenia \\
Red blood cells & Anemia \\
Nerves (myelin) & Peripheral neuropathy \\
Nuclear protein (ANA) & Autoimmune symptoms \\
\hline
\end{tabular}

Table 5. Regions of HIV that resemble normal cellular proteins

\begin{tabular}{lll}
\hline \multicolumn{1}{c}{ Normal cellular protein } & HIV region & Relation \\
\hline 1 HLA & gp120; gp41 & Sequence \\
& Nef; P17 & Sequence \\
& gp41 & Sequence \\
3 IL-2R & LTR & Sequence \\
4 Thymosin & Nef & Sequence \\
5 Epithelial cells & P17 & Serology \\
6 Astrocytes & P17 & Serology \\
7 Interferon & P17; gp41 & Serology \\
8 Vasoactive intestinal peptide & LTR & Sequence \\
& gp120 & Sequence \\
9 Neuroleukin (phosphohexose & gp120 & Serology \\
$\quad$ isomerase) & & Sequence \\
10 Ig & gp120 & Serology \\
11 Neurotoxin & Nef & Sequence \\
12 Protein kinase & Nef & Sequence \\
\hline
\end{tabular}

show a relationship to normal cellular proteins by serologic and molecular comparisons (Table 5); this observation has placed attention on autoantibodies as a factor in AIDS pathogenesis (73). The viral protein receiving the most attention is the envelope gp120 that shares sequence similarity with HLA (particularly the $\beta$ chain). Some researchers have demonstrated that antibodies to HIV can cross-react with certain MHC antigens on normal cells $(73,74)$. Thus, this autoimmune response may be contributing to the loss of CD4+ cells by "molecular mimicry."

Clearly, autoantibodies can be involved in the loss of neutrophils and platelets and in peripheral neuropathy. Plasmapheresis of these individuals leads to a return of the neutrophil and platelet counts and a remission in the neurologic disorder (75). However, this procedure does not appear to affect the CD4+ cell counts in these individuals (Kiprov D, personal communication). Thus, whether autoantibodies to CD4+ cells are responsible for the gradual loss of these lymphocytes and increased immune pathogenesis is still not clear.

\section{DISCUSSION}

We have reviewed certain features of HIV and the host immune response that can potentially determine the extent of pathogenesis leading to AIDS in the infected individual (Table 6). Certainly, the particular virus infecting the host can influence the extent of virus spread. For example, if it replicates well in the peripheral white cells in the individual, and has a wide cellular host range, this type of virus could hasten the pathogenic process. Moreover, the ability of the virus to kill white cells may determine how quickly the immune system is compromised by this infection. Yet it is conceivable that a very fast replicating cytopathic agent entering the host might be better recognized by the immune system and be suppressed more easily. Thus, a slowreplicating virus could be the more pathogenic type. This question can best be answered through animal model systems such as those involving different strains of the simian immunodefi-
Table 6. Potential viral and host factors influencing progression to disease

\begin{tabular}{l} 
Virus \\
Emergence of virulent HIV strains \\
Enhanced cellular host range \\
Increased cytopathic properties \\
Resistance to neutralization \\
Sensitivity to enhancing antibodies \\
Host \\
Decrease in neutralizing antibodies \\
Presence of enhancing antibodies \\
Decrease in CD8+ cell antiviral response \\
\hline
\end{tabular}

ciency virus. Finally, HIV could infect and remain latent in the host. This state would certainly assure survival of not only the agent but also the infected host. In this regard, efforts to induce or maintain a state of latency would be acceptable therapeutic approaches.

A major parameter that appears to influence the extent of pathogenesis is the host immune response to HIV. By neutralizing antibodies to some extent and certainly by mounting a strong $\mathrm{CD} 8+$ cell response (cytotoxic or suppressing), the virus could be kept "in check" for the lifetime of the host. If active early, the individual might even be cured of the infection. Many other viruses (e.g. herpes) are maintained for life in the host in a "silent" repressed state.

As physicians and basic researchers directing our efforts to finding a solution to the problem of AIDS, we must recognize that attacks on the virus itself or approaches to enhance the immune response of the host against HIV can be helpful in delaying the progression to disease or even completely arresting the viral infection. Many antiviral drugs have been developed, but they work primarily against reverse transcriptase (76). Thus, those products would limit the early steps in virus infection but not affect the virus-infected cells. Thus far, only tricosanthin (77) appears to act selectively against HIV-infected cells, but this observation and its clinical relevance require further study.

No drug has yet been found to induce a strong cellular immune response against the virus. These therapies are needed. Recently, postinfection vaccination with the viral envelope gp 160 has been suggested as a method for enhancing the immune response (78). This possibility also requires further evaluation and confirmation.

Our laboratory is directing its efforts at determining whether the Nef protein (after purification) can be used early in infection to block the replication of the relatively nonpathogenic strain so that it would not go through further replicative cycles to emerge as a "virulent" strain. We are also directing our efforts at defining the CD8+ cell factor with hopes that its purification in the laboratory or its de novo synthesis in vivo might lead to effective antiviral therapy. In this regard, approaches that could induce strong CD8+ cell-suppressing activity in the host merit much additional attention, but, as noted above, selective effects on the cellular immune response have not yet been observed with any immune-modulating drugs.

What is clear from these and other studies in our laboratory is that long-term survivors-individuals living more than 8 y (some for as long as $13 \mathrm{y}$ ) after infection, with normal CD4+ cell counts-have characteristics expected of a healthy carrier. They express a virus that is relatively nonpathogenic, have a strong CD8+ cell antiviral response, and do not produce enhancing antibodies (19). These individuals offer great hope to those infected. Their continued study could uncover other secrets to a normal lifespan, despite the continual presence of HIV infection.

Finally, approaches for a vaccine for prevention appear most important, particularly for those parts of the world in which the virus spreads at a rapid rate despite extensive educational programs. For these immunizations, the particular epitopes on the viral envelope required for efficient control need to be defined. 
They should be distinguished from those regions that may enhance virus infection through the ADE mechanism. Those conducting extensive vaccination of individuals with model vaccines should consider the potential danger of inducing enhancing antibodies in the host, as well as autoimmune phenomena that result from responses to viral proteins that are shared by normal cellular components within the host $(73,74,79)$.

\section{CONCLUSION}

We have come a long way in our attack on HIV since it emerged as a major infection in the early 1980s. Extensive information about the biology, molecular biology, and immunology of HIV infection is known, but many mysteries remain. Challenges to the scientific community include identifying the major cause of the loss of CD4+ lymphocytes in the blood, understanding the etiology of neurologic symptoms in the host, and defining the variety of factors that permit long-term survival in some infected individuals (19). Answers to these and other questions will eventually become known, and appropriate therapies will be found. However, HIV is a "moving target," and unless support, both financial and scientific, is continually available, AIDS will equal the other major epidemics that have hit and devastated global populations throughout history.

\section{REFERENCES}

1. Dalgleish A, Beverley P, Clapham P 1984 The CD4 (T4) antigen is an essential component of the receptor for the AIDS retrovirus. Nature 312:763-766

2. Klatzmann D, Champagne E, Chamaret S 1984 T-lymphocyte T4 molecule behaves as receptor for human retrovirus LAV. Nature 312:767-771

3. Levy JA, Shimabukuro J, McHugh T, Casavant C, Stites D, Oshiro L 1985 AIDS-associated retroviruses (ARV) can productively infect other cells besides human $T$ helper cells. Virology 147:441-448

4. Castro BA, Cheng-Mayer C, Evans LA, Levy JA 1988 HIV heterogeneity and viral pathogenesis. AIDS :2:s17-s28

5. Tateno M, Gonzalez-Scarano F, Levy JA 1989 The human immunodeficiency virus can infect CD4-negative human fibroblastoid cells. Proc Natl Acad Sci USA 86:4287-4290

6. Clapham PR, Weber JN, Whitby D, McIntosh K, Dalgleish AG, Maddon PJ, Deen KC, Sweet RW, Weiss RA 1989 Soluble CD4 blocks the infectivity of diverse strains of HIV and SIV for T cells and monocytes but not for brain and muscle cells. Nature 337:368-370

7. Kikikawa R, Koyanagi Y, Harada S 1986 Differential susceptibility to the acquired immunodeficiency syndrome retrovirus in cloned cells of human leukemic T cell line Molt-4. J Virol 57:1157-1162

8. Gallaher WR 1987 Detection of a fusion peptide sequence in the transmembrane protein of human immunodeficiency virus. Cell 50:327-328

9. Levy JA 1989 Human immunodeficiency viruses and the pathogenesis of AIDS. JAMA 261:2997-3006

10. Koito A, Hattori T, Murakami T, Matsushita S, Maede Y, Yamamoto T, Takatsuki K 1989 A neutralizing epitope of human immunodeficiency virus type 1 has homologous amino acid sequences with the active site of interalpha-trypsin inhibitor. Int Immunol 1:613-618

11. Hattori T, Koito A, Takatsuki K, Kodi H, Katanuma N 1989 Involvement of tryptase-related cellular protease(s) in human immunodeficiency virus type 1 infection. FEBS Lett 248:48-52

12. Harouse JM, Bhat S, Spitalnik SL, Laughlin M, Stefano K, Silberberg DH, Gonzalez-Scarano F 1991 Inhibition of entry of HIV-1 in neural cell lines by antibodies against galactosyl ceramide. Science 253:320-323

13. Weiss RA 1988 Receptor molecule blocks HIV. Nature 331:15

14. Daar ES, Li XL, Moudgil T, Ho DD 1990 High concentrations of recombinant soluble CD4 are required to neutralize primary human immunodeficiency virus type 1 isolates. Proc Natl Acad Sci USA 87:6574-6578

15. Barre-Sinoussi F, Chermann J-C, Rey F, Nugeyre MT, Chamaret S, Gruest J, Dauguet C, Axler-Blin C, Vezinet-Brun F, Rouzioux C, Rozenbaum W, Montagnier L 1983 Isolation of a T-lymphotropic retrovirus from a patien at risk for acquired immune deficiency syndrome (AIDS). Science 220:868871

16. Popovic M, Sarngadharan MG, Read E, Gallo RC 1984 Detection, isolation and continuous production of cytopathic retroviruses (HTLV-III) from patients with AIDS and pre-AIDS. Science 224:497-500

17. Levy JA, Hoffman AD, Kramer SM, Landis JA, Shimabukuro JM, Oshiro LS 1984 Isolation of lymphocytopathic retroviruses from San Francisco patients with AIDS. Science 225:840-842

18. Lifson JD, Reyes GR, McGrath MS, Stein BS, Engleman EG 1986 AIDS retrovirus induced cytopathology: giant cell formation and involvement of CD4 antigen. Science 232:1123-1127

19. Levy JA 1988 The mysteries of HIV: challenges for therapy and prevention. Nature 333:519-522

20. Tateno M, Levy JA 1988 MT-4 plaque formation can distinguish cytopathic subtypes of the human immunodeficiency virus (HIV). Virology 167:299301

21. Levy JA 1990 Changing concepts in HIV infection: challenges for the 1990's. AIDS 4:1051-1058

22. Asjo B, Albert J, Karlsson A, Morfeldt-Mamson L, Biberfeld G, Lidman K Fenyo EM 1986 Replicative properties of human immunodeficiency virus from patients with varying severity of HIV infection. Lancet 2: 660-662

23. Hoxie JA, Haggarty BS, Rackowski JL, Pilsbury N, Levy JA 1985 Persistent noncytopathic infection of human lymphocytes with AIDS associated retrovirus (ARV). Science 229:1400-1402

24. Price RW, Brew B, Sidtis J, Rosenblum M, Scheck A, Clearly P 1988 The brain in AIDS: central nervous system HIV-1 infection and AIDS dementia complex. Science 239:586-592

25. Levy JA, Evans L, Cheng-Mayer C, Pan L-Z, Lane A, Staben C, Dina D, Wiley C, Nelson J 1987 The biologic and molecular properties of the AIDSassociated retrovirus that affect antiviral therapy. Ann Inst Pasteur 138:101111

26. Cheng-Mayer C, Weiss C, Seto D, Levy JA 1989 Isolates of human immunodeficiency virus type 1 from the brain may constitute a special group of the AIDS virus. Proc Natl Acad Sci USA 80:8575-8579

27. Epstein LG, Kuiken C, Blumberg BM, Hartman S, Sharer LR, Clement M, Goudsmit J 1991 HIV-1 V3 domain variation in brain and spleen of children with AIDS: tissue-specific evolution within host-determined quasispecies. Virology 180:583-590

28. Wiley CA, Schrier RD, Denaro FJ, Nelson JA, Lampert PW, Oldstone MBA 1986 Localization of cytomegalovirus proteins and genome during fulminant central nervous system infection in an AIDS patient. $J$ Neuropathol Exp Neurol 45:127-139

29. Berger J, Levy JA 1992 The human immunodeficiency virus, type 1, the virus and its role in neurologic diseases. Semin Neurol 12:1-9

30. Brenneman DE, Westbrook GL, Fitzgerald SP, Ennist DL, Elkins KL, Ruff MR, Pert CB 1988 Neuronal cell killing by the envelope protein of HIV and its prevention by vasoactive intestinal peptide. Nature 335:639-642

31. Sabatier J-M, Vives E, Mabrouk K, Benjouad A, Rochat H, Duval A, Hue B, Bahraoui E 1991 Evidence for neurotoxic activity of tat from human immunodeficiency virus type 1. J Virol 65:961-967

32. Giuliain D, Vaca K, Noonan CA 1990 Secretion of neurotoxins by mononuclear phagocytes infected with HIV-L. Science 250:1593-1596

33. Pulliam L, Herndier BG, McGrath MS 1991 Human immunodeficiency virusinfected macrophages produce soluble factors that cause histological and neurochemical alterations in cultured human brains. J Clin Invest 87:503512

34. Serwadda D, Mugerwa RD, Sewankambo NK, Lwegaba A, Carswell JW, Kirya GB, Bayley AC, Downing RG, Tedder RS, Clayden SA, Weiss RA, Dalgleish AG 1985 Slim disease: a new disease in Uganda and its association with HTLV-III infection. Lancet 2:849-852

35. Nelson JA, Wiley CA, Reynolds-Kohler C, Reese CE, Margaretten W, Levy JA 1988 Human immunodeficiency virus detected in bowel epithelium from patients with gastrointestinal symptoms. Lancet 1:259-262

36. Polak JM, Pearse AGE, Heath CM 1975 Complete identification of endocrine cells in the gastrointestinal tract using semithin-thin sections to identify motilin cells in human and animal intestine. Gut 16:225-229

37. Gill MJ, Sutherland LR, Church DL 1992 Gastrointestinal tissue cultures for HIV in HIV-infected/AIDS patients. AIDS 6:553-556

38. Winkelstein Jr W, Lyman DM, Padian N, Grant R, Samuel M, Wiley JA Anderson RE, Lang W, Riggs J, Levy JA 1987 Sexual practices and risk of infection by the human immunodeficiency virus: The San Francisco Men's Health Study. JAMA 257:321-325

39. Barnett S, Barboza A, Wilcox CM, Forsmark CE, Levy JA 1991 Characterization of human immunodeficiency virus type 1 strains recovered from the bowel of infected individuals. Virology 182:802-809

40. Cheng-Mayer C, Seto D, Tateno M, Levy JA 1988 Biologic features of HIV that correlate with virulence in the host. Science 240:80-82

41. York-Higgins D, Cheng-Mayer C, Bauer D, Levy JA, Dina D 1990 Cellular host range, replication, and cytopathicity are linked to the envelope region of the viral genome. J Virol 64:4016-4020

42. O'Brien WA, Koyanagi Y, Namazie A, Zhao J-Q, Diagne A, Idler K, Zack JA, Chen ISY 1990 HIV-1 tropism for mononuclear phagocytes can be determined by regions of gp 120 outside the CD4-binding domain. Nature 348:6973

43. Shioda T, Levy JA, Cheng-Mayer C 1991 Macrophage and T-cell line tropisms of HIV-1 are determined by specific regions of the envelope gp 120 gene. Nature 349:167-169

44. Huang AS, Palma EL, Hewłett N 1974 Pseudotype formation between enveloped RNA and DNA viruses. Nature 252:743-745

45. Cheng-Mayer C, Shioda T, Levy JA 1991 Host range, replicative, and cytopathic properties of human immunodeficiency virus type 1 are determined by very few amino acid changes in tat and gp 120. J Virol 65:6931-6941

46. LaRosa GJ, Davide JP, Weinhold K, Waterbury JA, Profy AT, Lewis JA Langlois AJ, Dreesman GR, Boswell RN, Shadduck P, Holley LH, Karplus M, Bolognesi DP, Matthews TJ, Emini EA, Putney SD 1990 Conserved sequence and structural elements in the HIV-1 principal neutralizing determinant. Science 249:932-935

47. Takeuchi A, Akutsu M, Murayama K, Shimizu N, Hoshino H 1991 Host range mutant of human immunodeficiency virus type 1 : modification of cell tropism by a single point mutation at the neutralization epitope in the env gene. J Virol 65:1710-1718 
48. McKeating JA, Gow J, Goudsmit J, Pearl LH, Mulder C, Weiss RA 1989 Characterization of HIV-1 neutralization escape mutants. AIDS 3:777-784

49. Luciw PA, Cheng-Mayer C, Levy JA 1987 Mutational anlaysis of the human immunodeficiency virus (HIV): the orf-B region down-regulates virus replication. Proc Natl Acad Sci USA 84:1434-1438

50. Folks TM, Bednarik DP 1992 Mechanisms of HIV-1 latency. AIDS 6:3-16

51. Cheng-Mayer C, Ianello P, Shaw K, Luciw PA, Levy JA 1989 Differential effects of Nef on HIV replication: implications for viral pathogenesis in the host. Science 246:1629-1632

52. Levy JA, Mackewicz C, Cheng-Mayer C 1991 Natural antiviral responses in HIV infection. Seventh International Conference on AIDS, Florence, Italy, p 58(abstr)

53. Weiss RA, Clapham PR, Weber JN, Dalgleish AG, Lasky LA, Berman PW 1986 Variable and conserved neutralization antigens of human immunodeficiency virus. Nature 324:572-575

54. Cheng-Mayer C, Homsy JM, Evans LA, Levy JA 1988 Identification of HIV subtypes with distinct patterns of sensitivity to serum neutralization. Proc Natl Acad Sci USA 85:2815-2819

55. Homsy J, Meyer M, Levy JA 1990 Serum enhancement of human immunodeficiency virus (HIV) correlates with disease in HIV-l infected individuals. J Virol 64:1437-1440

56. Homsy J, Meyer M, Tateno M, Clarkson S, Levy JA 1989 The Fc and not the CD4 receptor mediates antibody enhancement of HIV infection in human cells. Science 244:1357-1360

57. Robinson Jr WE, Montefiori DC, Mitchell WM 1988 Antibody-dependent enhancement of human immunodeficiency virus type 1 infection. Lancet 1:790-794

58. Homsy J, Tateno M, Levy JA 1988 Antibody-dependent enhancement of HIV infection. Lancet 1:1285-1286

59. Kliks SC, Wu WW, Levy JA 1991 V3 epitopes can mediate antibody neutralization and enhancement of HIV-1 infection. Seventh International Conference on AIDS, Florence, Italy, p 40(abstr)

60. Takeda A, Sweet RW, Ennis FA 1990 Two receptors are required for antibodydependent enhancement of human immunodeficiency virus type 1 infection: CD4 and Fc-kappaR. J Virol 64:5605-5610

61. Robinson WE, Montefiori DC, Mitchell WM 1990 Complement-mediated antibody-dependent enhancement of HIV-1 infection requires CD4 and complement receptors. Virology 175:600-604

62. Robinson Jr EW, Gorny MK, Xu J-Y, Mitchell WM, Zolla-Pazner S 1991 Two immunodominant domains of gp41 bind antibodies which enhance human immunodeficiency virus type 1 infection in vitro. J Virol 65:41694176

63. Bauke RB, Spear PB 1979 Membrane proteins specified by herpes simplex viruses. V. Identification of an Fc-binding glycoprotein. J Virol 32:779-789

64. McKeating JA, Griffiths PD, Weiss RA 1990 HIV susceptibility conferred to human fibroblasts by cytomegalovirus-induced Fc receptor. Nature 343:659_ 661

65. Robert-Guroff M, Brown M, Gallo R 1985 HTLV-III neutralizing antibodies in patients with AIDS and AIDS-related complex. Nature 316:72-74

66. Halstead SB 1979 In vivo enhancement of dengue virus infection in rhesus monkeys by passively transferred antibody. J Infect Dis 140:527-533

67. Walker CM, Moody DJ, Stites DP, Levy JA 1986 CD8+ lymphocytes can control HIV infection in vitro by suppressing virus replication. Science 234:1563-1566

68. Nixon DF, McMichael AJ 1991 Cytotoxic T-cell recognition of HIV proteins and peptides. AIDS 5:1049-1059

69. Mackewicz C, Levy JA 1992 CD8 + cell anti-HIV activity: non-lytic suppression of virus replication. AIDS Res Hum Retroviruses 8:1039-1050

70. Mackewicz CE, Ortega HW, Levy JA 1991 CD8+ cell anti-HIV activity correlates with the clinical state of the infected individual. $J$ Clin Invest 87:1462-1466

71. Walker CM, Levy JA 1989 A diffusible lymphokine produced by CD8 + T lymphocytes suppresses HIV replication. Immunology 66:628-630

72. Mackewicz C, Legg H, Ortega H, Levy JA 1991 CD8+ lymphocytes from HIV-1 seropositive individuals block HIV replication in CD4+ lymphocytes by inhibiting viral RNA synthesis. Seventh International Conference on AIDS, Florence, Italy, p 74(abstr)

73. Morrow WJW, Isenberg DA, Sobol RE, Stricker RB, Kieber-Emmons T 1991 AIDS virus infection and autoimmunity: a perspective of the clinical, immunological, and molecular origins of the autoallergic pathologies associated with HIV disease. Clin Immunol Immunopathol 58:163-180

74. Golding H, Robey FA, Gates III FT, Linder W, Beining PR, Hoffman T, Golding B 1988 Identification of homologous regions in human immunodeficiency virus I gp4l and human MHC Class II beta 1 domain. I. Monoclonal antibodies against the gp41-derived peptide and patients' sera react with native HLA Class II antigens, suggesting a role for autoimmunity in the pathogenesis of acquired immune deficiency syndrome. J Exp Med 167:914-923

75. Kiprov D, Pfaeffl W, Parry G, Lippert R, Lang W, Miller R 1988 Antibodymediated peripheral neuropathies associated with ARC and AIDS: successful treatment with plasmapheresis. J Clin Apheresis 4:3-7

76. Yarchoan R, Mitsuya H, Broder S 1989 Clinical and basic advances in the antiretroviral therapy of human immunodeficiency virus infection. Am J Med 87:191-200

77. McGrath MS, Hwang KM, Caldwell SE, Gaston I, Luk K-C, Wu P, Ng VL, Crowe S, Daniels J, Marsh J, Deinhart T, Lakas PV, Vannari JC, Yeung HW, Lifson JD 1989 GLQ223: an inhibitor of human immunodeficiency virus replication in acutely and chronically infected cells of lymphocyte and mononuclear phagocyte lineage. Proc Natl Acad Sci USA 86:2844-2848

78. Redfield RR, Birx DL, Ketter N, Tramond E, Polonis V, David C, Brundage JF, Smith G, Johnson S, Fowler A, Wierzba T, Shafferman A, Volvoyitz F, Oster C, Burke DS, Military Medical Consortium for Applied Retroviral Research 1991 A phase I evaluation of the safety and immunogenicity of vaccination with recombinant gp 160 in patients with early human immunodeficiency virus infection. N Engl J Med 324:1677-1683

79. Levy JA 1988 Can an AIDS vaccine be developed? Transfus Med Rev 2:264271

80. Cheng-Mayer C, Shioda T, Levy JA 1992 Small regions of the env and tat genes control cellular tropism, cytopathology and replicative properties of HIV-1. In: Rossi GB, Beth-Giraldo E, Chieco-Bianchi L, Dianzani F, Giraldo G, Verani P (eds) Science Challenging AIDS. S. Karger AG, Basel, pp 188195

\section{FLOOR DISCUSSION}

Dr. Yolken: Given that an individual has multiple strains of HIV, how do you determine which is predominant: the cytopathic strain, the strain that is neutralized, or the one that is enhanced? Do you test multiple strains from the same individual?

Dr. Levy: That has always been a major concern, particularly of the molecular biologists who are cloning from the white cells directly with polymerase chain reactions. They ask, "Is the virus identified the one that was cultured in vitro?" First, we do look at multiple strains from the same individual. But also we follow a number of individuals over time. If we see the same pattern under the same conditions, i.e. we culture a virus at an early time in infection and it has none of the characteristics of virulence and later we isolate a virus and it has virulent properties, we conclude that we are seeing the major type that is causing disease in that individual. We will not know for sure about virulence until we can experiment in animal models.

Dr. Schwartz: Have you looked at your antibodies-the ones that show either neutralization or enhancement-for ADCC (antibody-dependent cellular cytotoxicity)-mediated activity? I wonder if that alone could explain how it might facilitate binding to the macrophage as a target in one case, but serve in a hostprotective capacity in the other.

Dr. Levy: Most of the antienvelope antibodies will participate in ADCC, but our assays would not be affected by any ADCC activity.

Dr. Schwartz: Could you tell us anything more about the soluble factor? Is it a polypeptide? Do you have any estimate of its size?

Dr. Levy: Well, it is heat stable. We believe it is about 30000 molecular weight or smaller. One of the problems is that it is produced at only about $4 \mathrm{U} / \mathrm{mL}$. We can obtain a little bit more by certain procedures, but it has been extremely difficult to recover enough to understand yet the nature of the factor.

Dr. Levinson: Do these CD8 + cells have to come from HIVinfected individuals, or is this soluble factor constitutively produced by normal CD8 cells?

Dr. Levy: We do not believe that one needs to be infected by HIV to produce the factor. We have been able to get evidence of the factor with some normal CD8+ cells; at least we think it is the same cytokine. However, it is much easier to find the factor in cells from someone who has been exposed to HIV.

Dr. Levinson: But these cells must be constitutively producing this factor. They do not need to recognize anything on the CD4infected cells because of the way you set up your assay.

Dr. Levy: In the case of the factor, we usually increase its production with phytohemagglutinin. But we have found that in the cell-cell contact system we can take the CD8+ cells directly out of the blood of an HIV-infected individual and mix them with CD4+ cells. Antiviral activity is observed.

Dr. Gupta: Those enhancing and neutralizing antibodies are interesting. Have you looked at IgG subclass distribution? Is there a differential subclass preference between them? I think this point is especially important with respect to the distribution of IgG subclass receptors on macrophages. Also, can you tell me a little more about how those antibodies are getting the virus 
inside the $\mathrm{T}$ cells, because the $\mathrm{Fc}$ receptor is on the CD8+ cells, not on CD4+ cells?

Dr. Levy: Both the enhancing and neutralizing antibodies are IgG. We have not been able to separate them yet into subclasses to see if there will be a distinction. We would like to do that. As to your second point, one can block the enhancement in CD4+ cells with IgG. We have been told by researchers on $\mathrm{Fc}$ receptors that there is probably an Fc-like receptor on T lymphocytes, and that is the receptor involved.

Dr. Schreiber: That last point is controversial in terms of whether or not there is an $\mathrm{Fc}$ receptor on $\mathrm{T}$ lymphocytes.

I would like to focus on this macrophage-binding property. Our laboratory does not work on HIV, so some of these comments may be a little naive, but if I understand correctly, you have a region on the $\mathrm{V} 3$ portion of the molecule, which you are able to mutate, that facilitates tropism. Is that actually binding to the macrophage site? And if it is binding, what molecules or what sequence on the macrophage surface is it interacting with? You showed us sequence data with specific change to an aspartic acid that blocks that interaction. That sequence could be quite important.

Dr. Levy: You are right, but these are very tough experiments. We can see binding, with similar affinity, to the CD4 molecule, but we do not think that alone is the answer. Perhaps there is a specific macrophage receptor. We are now looking at the relative ability of cell membranes to cleave the gp 120 and thus bring about virus infection. Perhaps the cleavage site has been changed so that the protease within the macrophage membrane is better able to recognize it or alternatively, without cleaving, the virus enters best. This is probably our best approach at this time.

Dr. Ochs: There is an old dictum among immunologists that the more one is exposed to an antigen, the higher the affinity of the antibody. It looks to me as if you are saying just the opposite. I am bringing this up because there is one strategy, which I think Dr. Salk has pursued, to immunize patients who are HIVinfected to turn around their immune status. Is what you are saying just the opposite, or did it just happen that you went from high-affinity neutralizing antibody to low-affinity enhancing antibody in this one patient?

Dr. Levy: First, one must recognize that the virus is also evolving. Until we can look at the affinity of the antibody to a particular virus, we will not know the answer. But we have seen this type of response in three of five individuals; the antibody has changed. In some cases the virus has changed. The dynamics depend on those two parameters. One cannot just say that over time there should be better neutralization. In regard to your other point, one of my concerns with widespread vaccination is that the immune response might be increased in the wrong way. You may induce autoantibodies. You may produce enhancing antibodies in the vaccinees. The proponents of this strategy are not looking at that aspect and it should be considered.

Dr. Fischer: Given your evolving virus, have you looked at early AZT (azidothymidine) treatment? It is unclear what the role of true resistance to AZT is, but is there possibly an effect on the evolution of the virus itself into the more cytopathic form?

Dr. Levy: That was also one of our concerns with AZT, not only with the resistance to the drug, but also with its effects on CD8+ cells. Alan Landey and Carl Mackowicz in our group have asked these questions and have found no correlation with the biologic properties of the HIV-1 strain and resistance to AZT. Moreover, AZT has shown no detrimental effect on CD8+ cell suppression of HIV replication.

Dr. Starr: Can you detect suppression by CD8+ cells in pediatric patients, or have you only looked at adults?

Dr. Levy: We have looked at children, and they have this CD8+ cell activity. In fact, one of our very first cases was a young girl who was not releasing virus; we could get the virus out of the blood only by removing CD8+ cells. Over time, we found that the child was losing this CD8+ cell response, and this observation suggested the use of adoptive transfer. Dr. Diane Wara did some experiments with us to ask what would happen if we just added the CD8+ cells to the cell culture. We found that they could block HIV replication, but they also turned off immunoglobulin synthesis. Therefore, adoptive transfer might be harmful. Nevertheless, this approach is under study with adults in some institutions today.

Dr. Starr: Do you see any difference between pediatric and adult cases in the frequency or the magnitude of this phenomenon?

Dr. Levy: Not really. We have even had some infants who are not virus-infected, at least after 15 mo of study, and yet very early on they show CD8 + cell, anti-HIV responses. This observation suggests that they have been exposed to HIV antigen or perhaps were infected but eliminated the virus.

Dr. Steigbigel: Concerning the potential mechanism of the changes in the V3 loop that allow macrophage tropism, is there any concomitant change in infection of $\mathrm{T}$ lymphocytes or cell lines with the increased ability to infect the macrophages? And as a corollary, since it may be endopeptidases that are responsible, do you want to speculate on what endopeptidases might be in one cell and not in the other, if there is no concomitant change?

Dr. Levy: What I did not show was that when a viral V3 loop is modified to show macrophage tropism, the T-cell tropism is lost. So there could be concomitant changes that occur. As far as the proteases are concerned, I hope we will have better leads to that process within the next year.

Dr. Wara: In San Francisco, we have noticed a very low transmission rate of HIV to infants born to HIV-infected pregnant women identified before the last trimester. Our transmission rate is around $12 \%$. Do you think this is related to viral strain, to what is going on in the delivery room, or to something as yet unidentified?

Dr. Levy: That has been a mystery to us as well. What goes on in the delivery room is one factor, and the other is the clinical state of the mother. If the mother is healthy and she has a strong $\mathrm{CD} 8+$ cell response that suppresses the virus, there will not be much free virus in the blood to transfer to the infant in utero or during passage through the birth canal. In half of the cases we have studied, the infection has occurred at the time of birth. Virus is not found in the cord blood but is recovered 1 or $2 \mathrm{mo}$ later. Thus, we believe the infection occurred during birth. That evidence, if confirmed, is extremely encouraging, because it says that if we cleanse the birth canal of the mother before delivery and clean the child immediately after birth we may be able to have the greatest effect on preventing virus transmission. I want to take this opportunity to say to anyone who can influence obstetricians involved in delivery of newborns from HIV-infected mothers, try this approach. 